\title{
Assess the Knowledge Regarding Effect and Side Effect of Folic Acid and Ferrous Sulphate Among Anemic Women
}

\author{
Achita Sawarkar, Priyanka R, Divyashree R, Nayana R, Sonali S, Rasika S and Minakshi M \\ Smt. Radhikabai Meghe Memorial College of Nursing, Sawangi (Meghe), Wardha,Datta Meghe \\ Institute of Medical Sciences (Deemed to be University) Maharashtra, India \\ Corresponding author email: achitasawarkar5@gmail.com
}

\section{ABSTRACT}

Folic acid and ferrous sulphate are prescription drugs used to treat anemia caused by a deficiency in iron or folic acid. Anemia is caused by an iron deficiency, which is the most common cause of anemia in the globe. Usually women living in villages and rural area do not have knowledge regarding iron and folic acid supplements. To minimize the danger of iron deficiency in the blood, ferrous and folic acid supplements are utilized. Iron is necessary for the body's red blood cell synthesis as well as overall health. Ones who consume oral iron develop black stools, abdominal cramps, and epigastria discomfort, which have no clinical significance but can mask the diagnosis of continued gastrointestinal blood loss. Objectives Of The Studies: 1.To assess the existing knowledge regarding effect and side effect of folic acid and ferrous sulphate among the anemic women 2. To associate knowledge regarding side effect of folic acid and ferrous sulphate among the anemic women with demographic variables This study was carried out using a descriptive research approach. The data from anemic women was collected using a non-probability - convenient sampling techniques was used. The data was gathered using a structured questionnaire. 80 anemic women are selected to conduct the study from selected hospital in Wardha district. $85 \%$ of anemic women had an average level of knowledge, 15\% of respondents had a Good level of knowledge, and $0 \%$ of respondents had a poor or excellent level of understanding regarding the effects and adverse effects of folic acid and ferrous sulphate in anemic women. The study shows that the knowledge of the anemic women regarding folic acid and ferrous sulphate is average in most of the anemic women. Women need daily iron because they lose blood each month during their period. But some women have allergies to these supplements can cause various side effect by taking the supplements.

\section{KEY WORDS: FERROUS SULPHATE, FOLIC ACID, ANEMIC WOMEN.}

\section{INTRODUCTION}

Folic acid and ferrous sulphate are prescription drugs used to treat anemia caused by a deficiency in iron or folic acid. Anemia is caused by an iron deficiency, which is the most common cause of anemia in the globe.. Usually women living in villages and rural area do not have knowledge regarding iron and folic acid supplements. To minimize the danger of iron deficiency in the blood, ferrous and folic acid supplements are utilized (such as those caused by anemia or pregnancy).

Biosc Biotech Res Comm P-ISSN: 0974-6455 E-ISSN: 2321-4007

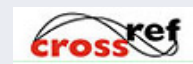

Identifiers and Pagination

Year: 2021 Vol: 14 No (9) Special

Issue Pages: 379- 382

This is an open access article under Creative

Commons License Attribn 4.0 Intl (CC-BY).
DOI: $h$ ttp://dx.doi.org/10.21786/bbrc/14.9.70
Iron is necessary for the body's red blood cell synthesis as well as overall health. Ones who consume oral iron develop black stools, abdominal cramps, and epigastria discomfort, which have no clinical significance but can mask the diagnosis of continued gastrointestinal blood loss .Iron is a necessary component for the production of hemoglobin in erythrocytes, and a shortage can result in anemia. Anemia affects an estimated 1.62 billion individuals $(24.8 \%)$ of the global population, including half a billion women of reproductive age. Preschool-aged children have the highest frequency (47.4\%), while males have the lowest prevalence (12.7\%), accounting for 25 percent of the global population.

Iron and folic acid deficiency anemia affects 46, 49, 39 , and 25\% of pregnant women in Africa, Southeast Asia, the mediterranean Region, and the United States, respectively. Anemia is common among women who are expecting in South Africa, with a prevalence rate of 7-29
Article Information

Received: $05^{\text {th }}$ June 2021

Accepted after revision: $18^{\text {th }}$ July 2021 
percent In India, iron deficiency anemia in women is a serious public health concern. According to data from three waves of the National Family Health Survey, iron deficiency anemia among women aged 15 to 49 years in India decreased by just 3.5 percent over the period (from 56.5 percent in 2005-2006 to 53.0 percent in 20152016). Iron-deficiency anemia increased in eight of the 27 states studied during the same time period: Delhi, Haryana, Himachal Pradesh, Kerala, Meghalaya, Tamil Nadu, Punjab, and Uttar Pradesh; Furthermore, several of these states (for example, Kerala) have failed to control the burden of iron deficiency anemia while having one of the highest state Human Development Index scores. According to the National Family Health Survey, in India, the occurrence of anemia among pregnant women has dropped from $57.9 \%$ to 50.3 percent. However, only $15 \%$ of women took iron and folic acid (IFA) supplements for the first 100 days of pregnancy throughout that decade(Rk et al., 2018).

\section{MATERIAL AND METHODS}

This study was conducted using a quasi-experimental research . To obtain data, a non-probability - convenient sampling approach was employed, and 80 anemic women from the hospital were chosen. After the ethical permission (Ref. no: DMIMS (DU)/IEC/2020-21/151).

Methods of data collection: For the present study the validated tool was used structured questionnaire. The tool was in English and Marathi local language. Structured knowledge questionnaire contained 20 multiple choice questions. Data was collected within 02 weeks by group members data collection was followed by knowledge. Permission from the concerned authorities is taken The tool content validity of this was done by various from different fields. Suggestion The proposed tool was incorporated, and appropriate modifications were made analysis was done by Intra class correlation. The data in selected hospital of Wardha and obtained the necessary. Permission from the concerned authorities of the hospital.

\section{RESULTS}

This section discusses the percentage-wise distribution of anemic women by demographic variables. From the study population, an appropriate sample of 80 patients was recruited from designated hospitals. Age, residence, family type, education, occupation, marital status, income, and knowledge and source of information about folic acid and ferrous sulphate were all used to describe the sample's characteristics. This section assesses the level of awareness of anemic women in a selected hospital on the effects and side effects of folic acid and ferrous sulphate. The following categories are used to categories the level of knowledge: poor, average, good, and excellent. According to the table above, 85\% of anemic women had an average degree of knowledge, while 15\% had a good knowledge. The minimum and highest knowledge scores were 6 and 14, respectively. The average knowledge score was 9.081.67, and the average knowledge score percentage was 45.438.38.

Table 1. Anemic Women are distributed in percentages based on their demographic traits $n=80$

\begin{tabular}{|c|c|c|}
\hline $\begin{array}{l}\text { Demographic } \\
\text { Variables }\end{array}$ & $\begin{array}{c}\text { No. of } \\
\text { anemic women }\end{array}$ & $\begin{array}{l}\text { Percentage } \\
\text { (\%) }\end{array}$ \\
\hline \multicolumn{3}{|l|}{ Age(yrs) } \\
\hline $18-23$ yrs & 28 & 35.0 \\
\hline $24-29$ yrs & 18 & 22.5 \\
\hline $30-35$ yrs & 19 & 23.8 \\
\hline$>35$ yrs & 15 & 18.8 \\
\hline \multicolumn{3}{|l|}{ Residence } \\
\hline Urban & 39 & 48.8 \\
\hline Rural & 41 & 51.3 \\
\hline \multicolumn{3}{|l|}{ Type of family } \\
\hline Nuclear & 38 & 47.5 \\
\hline Joint & 19 & 23.8 \\
\hline Extended & 23 & 28.8 \\
\hline \multicolumn{3}{|c|}{ Educational Status } \\
\hline Primary & 26 & 32.5 \\
\hline Secondary & 21 & 26.3 \\
\hline Graduate & 19 & 23.8 \\
\hline PG and above & 14 & 17.5 \\
\hline \multicolumn{3}{|l|}{ Occupation } \\
\hline Homemaker & 37 & 46.3 \\
\hline Labour & 18 & 22.5 \\
\hline Govt/Pvt Job & 18 & 22.5 \\
\hline Business & 7 & 8.8 \\
\hline \multicolumn{3}{|l|}{ Marital Status } \\
\hline Married & 47 & 58.8 \\
\hline Unmarried & 30 & 37.5 \\
\hline Widow & 3 & 3.8 \\
\hline \multicolumn{3}{|c|}{ Monthly family income(Rs) } \\
\hline 5000-10000 Rs & 11 & 13.8 \\
\hline 10001-15000 Rs & 25 & 31.3 \\
\hline 15001-20000 Rs & 27 & 33.8 \\
\hline >20000 Rs & 17 & 21.3 \\
\hline \multicolumn{3}{|c|}{$\begin{array}{l}\text { Knowledge about folic acid } \\
\text { and ferrous sulphate }\end{array}$} \\
\hline Yes & 37 & 46.3 \\
\hline No & 43 & 53.8 \\
\hline \multicolumn{3}{|c|}{ Source of knowledge } \\
\hline Friends & 18 & 22.5 \\
\hline Social Media & 16 & 20.0 \\
\hline Books & 21 & 26.3 \\
\hline Health Worker & 25 & 31.3 \\
\hline
\end{tabular}

\section{DISCUSSION}

The study's findings were addressed in relation to the objectives. The goal of this study was to see how much anemic women knew about the effects and adverse effects of folic acid and ferrous sulphate. Data was collected 
from 80 anaemic women in this study, which was done at a specified hospital in Wardha city and subjects were chosen using a purposive selection approach. The structural knowledge questionnaire was used to collect data. According to the findings, 85 percent of anaemic women had an average level of knowledge, 15\% had a Good level of knowledge, and 0\% had a bad or outstanding level of knowledge regarding the benefit and side effects of folic acid and ferrous sulphate in anaemic women.

Table 2. Assessment with level of knowledge score $\mathbf{n = 8 0}$

\begin{tabular}{|c|c|c|c|}
\hline \multirow{2}{*}{$\begin{array}{l}\text { Level of knowledge } \\
\text { score }\end{array}$} & \multirow{2}{*}{ Score Range } & \multicolumn{2}{|c|}{ Level of Knowledge Score } \\
\hline & & No of anemic women & Percentage \\
\hline Poor & $0-25 \%(1-5)$ & 0 & 0 \\
\hline Average & $26-50 \%(6-10)$ & 68 & 85 \\
\hline Good & $51-75 \%(11-15)$ & 12 & 15 \\
\hline Excellent & $76-100 \%(16-20)$ & 0 & 0 \\
\hline \multicolumn{2}{|c|}{ Minimum score } & \multicolumn{2}{|l|}{6} \\
\hline \multicolumn{2}{|c|}{ Maximum score } & \multicolumn{2}{|l|}{14} \\
\hline \multicolumn{2}{|c|}{ Mean knowledge score } & \multicolumn{2}{|c|}{$9.08 \pm 1.67$} \\
\hline \multicolumn{2}{|c|}{ Mean $\%$ Knowledge Score } & \multicolumn{2}{|c|}{$45.43 \pm 8.38$} \\
\hline
\end{tabular}

Graph 1: Assessment with knowledge score

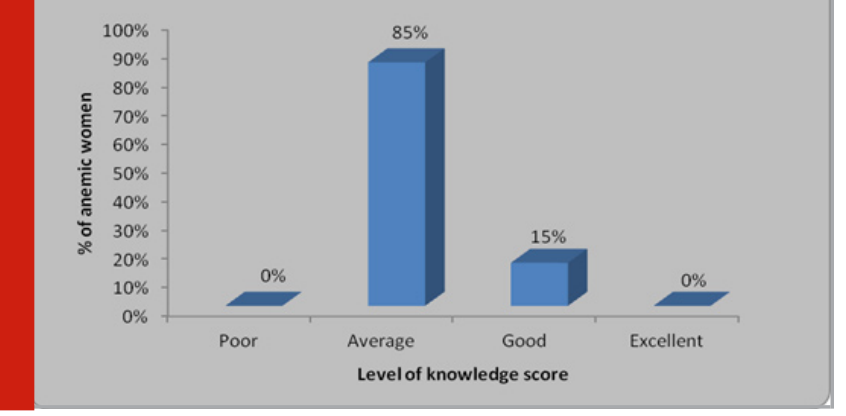

Pregnant women in Nepal have a high rate of iron deficiency anemia and poor adherence to iron and folic acid therapy. The purpose of this study was to see how effectively pregnant and postnatal women in Kathmandu understood and used iron and folic acid supplementation. A descriptive cross-sectional study approach was utilized in this investigation. With a sample size of 103, the data was obtained using a purposive sampling technique. All pregnant women who were more than 7 months pregnant and postnatal women who were less than 6 months pregnant were included in the study. Data was collected using a self-administered questionnaire. More over half of the respondents (51.5\%) were between the ages of 21 and 30. The respondents' average age was 30.58. There are 43 expectant moms (42\%) and 60 postnatal mothers (58\%) among those who responded. Sixty-five percent of respondents said that pregnant and postnatal women must take folic and iron tablets. Iron and folic acid consumption will prevent anemia, according to nearly sixty-nine percent of responders (57.3 percent). SPSS version 20 was used to analyse all of the collected data.
The participants' knowledge of iron and folic acid supplements was found to be adequate in 85.6 percent (88) of the cases. The data revealed that 78.6 percent (81) of the respondents followed the Nepal government's iron and folic acid guidelines, which required them to consume at least 180 tablets before giving birth. In comparison to the national status of 42 percent, the degree of knowledge and compliance rate of iron and folic acid supplements in Kathmandu is good, according to the Nepal Demographic Health Survey 2016. Iron and folic acid tablet knowledge is unrelated to compliance with iron and folic acid tablets. Compliance is the primary factor for responders' that they received adequate advice from a health worker, whereas the main reason for noncompliance is that they forgot to bring their tablet.

As a result, enhancing knowledge alone will not increase compliance; other factors such as counselling, Iron and folic acid pills are easily accessible and available, pill side effects, and family support all have an impact on iron and folic acid supplements compliance. All pregnant and postnatal women were aware with iron and folic acid supplementation treatments, had appropriate knowledge, and were mostly compliant with iron and folic acid supplementation, suggesting that compliance and knowledge levels in Kathmandu are satisfactory. Green leafy vegetables, pulses, legumes, and animal products were the most common sources of iron-rich diets, whereas iron-fortified meals were less common(Rai et al., 2016).

Folic acid (FA) supplementation is a critical intervention for avoiding nutritional deficits throughout maternity, and it has long-term consequences for both the mother and the infant. Nutritional insufficiency is caused by insufficient food consumption, which necessitates supplementation. FA is a necessary vitamin for a healthy pregnancy. Previous research has shown that pregnant women who are aware of the benefits of FA supplementation but do not take it while pregnant are more likely to experience problems with their babies. The purpose of this study was to examine Saudi maternity female's awareness and knowledge of FA supplementation, as well as to compare the results to prior Saudi community studies. We utilized a questionnaire to identify 406 Saudi expectant mothers between the ages of 18 and 65 who were subsequently tested for FA supplements usage during their pregnancy. Pregnant women who were involved completed a questionnaire and signed a permission form.

According to the findings, 38 percent of women between the ages of 31 and 40 became pregnant. Almost 96 percent of pregnant women are aware that they should take folic acid supplements throughout their pregnancy, and 5.9\% of women have a history of not taking folic acid supplements and having defective children. According to the present study's questionnaire survey, the benefits of taking FA supplements are known by 55.7 percent of expectant mothers. In previous pregnancies, , over 89 percent of women utilized FA. Saudi pregnant women are well-informed and aware of the benefits of taking 
a prenatal vitamin. Limited efforts should be made across the country at all hospitals and clinics to raise maternal nutrition knowledge during pregnancy. To gain a perspective in Saudi Arabia, nutritional counseling should be performed in rural regions(AlDuraibi \& AlMutawa, 2020)

\section{Recommendation:}

Based on the findings of the study, it is suggested that the following research be carried out.

1. To examine the existing knowledge of folic acid and ferrous sulphate, a comparable study may be done in both urban and rural areas.

2. This study can be conducted on large scale

3. This study can be done on urban area

4. This research can be carried out to examine public perceptions about folic acid and ferrous sulphate supplementation.

\section{CONCLUSION}

Women need daily iron because they lose blood each month during their period. But some women have allergies to these supplements can cause various side effect by taking the supplements. It is important that the women who are taking these supplements have the knowledge regarding these supplements. The primary goal of the study was to examine anaemic women's awareness of the effects and side effects of folic acid and ferrous sulphate.

\section{REFERENCES}

AlDuraibi, S., \& Al-Mutawa, J. (2020). Knowledge and awareness of folic acid usage in Saudi pregnant women in Riyadh city from 2019-2020. Journal of Family Medicine and Primary Care, 9(10), 5158-5164. https:// doi.org/10.4103/jfmpc.jfmpc_638_20

Anemia: Symptoms, Types, Causes, Risks, Treatment \& Management. (n.d.). Cleveland Clinic. Retrieved July 13, 2021, from https://my.clevelandclinic.org/health/ diseases/3929-anemia

Ferrous Sulphate-C-Folic Acid Oral: Uses, Side Effects, Interactions, Pictures, Warnings \& Dosing-WebMD. (n.d.). Retrieved July 13, 2021, from https://www.webmd. com/drugs/2/drug-18533/ferrous-sulphate-c-folic-acidoral/details

Prevalence and determinants of anemia among pregnant women in East Africa; A multi-level analysis of recent Demographic and Health Surveys. (n.d.). Retrieved July 13, 2021, from https://journals.plos.org/plosone/ article?id=10.1371/journal.pone. 0250560

Rai, S. S., Ratanasiri, T., Arkaravichien, T., Thapa, P., \& Koju, R. (2016). Compliance and its Determinants Regarding Iron and Folic Acid Supplementation during Pregnancy in Kathmandu, Nepal. Kathmandu University Medical Journal (KUMJ), 14(56), 311-317.

Rk, R., Ww, F., A, B., \& A, C. (2018). The burden of iron-deficiency anemia among women in India: How have iron and folic acid interventions fared? WHO South-East Asia Journal of Public Health, 7(1). https:// doi.org/10.4103/2224-3151.228423

WHO | Daily iron and folic acid supplementation during pregnancy. (n.d.). Retrieved July 13, 2021, from https:// www.who.int/elena/titles/daily_iron_pregnancy/en/ WHO | Global anemia prevalence and number of individuals affected. (n.d.). WHO; World Health Organization. Retrieved July 13, 2021, from https://www. who.int/vmnis/anemia/prevalence/summary/anemia _data_status_t2/en/ 